\title{
Use of Enhanced Green Fluorescent Protein to Optimize and Quantitate Infection of Target Cells with Recombinant Retroviruses
}

BioTechniques 26:924-930 (May 1999)

L.M. Cashion, L.A. Bare, S. Harvey, Q. Trinh, Y. Zhu and J.J. Devlin

Berlex Biosciences

Richmond, CA, USA

\begin{abstract}
Recombinant retroviral vectors are useful tools for gene transfer in both gene therapy and research applications. An enhanced form of green fluorescent protein has been incorporated into recombinant retroviruses as a marker to follow infected cells. In this paper, we extended the use of the fluorescent reporter to quantify protein expression using such analytical tools as fluorescent microscopy, flow cytometry and fluorescent plate reader analysis. These tools enabled us to rapidly assess the titer of recombinant retrovirus harvested from packaging cells and to optimize parameters for infection of different cell lines.
\end{abstract}

\section{INTRODUCTION}

Retroviral vectors facilitate gene transfer in both clinical and research environments $\quad(3,7-9,13,15,16,19,21$, 22). Exogenous coding regions can be inserted into the viral RNA in place of viral genes, which are then supplied in trans by the packaging cell line to produce replication-deficient viruses capable of infecting and integrating into the genomes of target cells $(2,7-9,14,16$ $18,21,22)$. Transient viral production systems utilize multicopy plasmids for expression of viral RNA and proteins, and high titer virus can be isolated $48 \mathrm{~h}$ after transfection of the packaging cell line $(1,8,9,12,20)$. Enhanced green fluorescent protein (EGFP) has been incorporated into retroviral vectors to follow transfection of the packaging cell line, measure viral titer and rapidly isolate infected cells $(1,3,4,6,9,13,14,16$, 18,19,21).

Wild-type green fluorescent protein from Aequorea victoria has been modifed in the chromophore region to enhance the intrinsic fluorescence $(1,3,6$, $11,22-24)$ and in the coding region using silent mutations to optimize expression in human cells $(19,23,24)$. Previous studies have demonstrated the utility of EGFP as a marker for gene transfer with recombinant retroviral vectors and the use of flow cytometry to identify and quantify infected cells $(1,3,4,9,13,15$, $16,18,19,21,22)$. In this report, we demonstrate that the fluorescent signal of EGFP is strong enough to be detected in living cells by more direct methods, including fluorescent microscopy $(9,14$, $16,19,21,22)$ and fluorescent microplate readers (22). These tools enable the researcher to actively monitor viral titer and infection efficiency during the course of an experiment.

\section{MATERIALS AND METHODS}

\section{Cell Lines and Culture Conditions}

The NIH-3T3 and PC-3 cells (ATCC, Rockville, MD, USA) were propagated in Dulbecco's modified Eagle medium (DMEM) (Life Technologies, Gaithersburg, MD, USA) supplemented with $10 \%$ calf serum (Hyclone Laboratories, Logan, UT, USA) and in Kaighn's F-12 medium (Irvine Scientific, Irvine, CA, USA) supplemented with 7\% fetal calf serum (FCS) (Hyclone Laboratories), respectively. The Phoenix cell line (provided by Gary Nolan, Stanford University, Stanford, CA, USA) was propagated in DMEM plus $10 \%$ FCS $(1,12)$.

\section{Construction of the Retroviral Plasmid for Expression of EGFP}

The EGFP expression plasmid used in these studies, pNOLein, is shown in Figure 1. The plasmid was constructed by ligating the 3.7-kb NheI fragment from pLein (CLONTECH Laboratories, Palo Alto, CA, USA) containing the coding region for EGFP and neo to the large NheI fragment of pLZRSLacZ(A) (Reference 12; provided by Gary Nolan) that contained the EpsteinBarr virus (EBV) sequences needed for extra-chromosomal replication. 


\section{Fluorescence Detection of Infected Cells}

A Labophot-2 ${ }^{\mathrm{TM}}$ Inverted Fluorescent Microscope (Nikon, Melville, NY, USA), equipped with fluorescein isothiocyanate (FITC) dichroic filter set (excitation at $450-490 \mathrm{~nm}$ and emission at $521 \mathrm{~nm}$ ) was used to visualize living cells. The reticule inside the eyepiece of the microscope was calibrated using a micrometer.

\section{Infection and Production of Recombinant Retroviruses}

For generation of recombinant retroviral stocks, Phoenix packaging cells were plated into 6-well plates (Corning Costar, Cambridge, MA, USA) at $2 \times$ $10^{6}$ cells per well. The next day, the cells were transfected with $2 \mu \mathrm{g}$ of the retroviral expression vector using calcium phosphate $(9,20)$. Forty-eight hours later, fluorescent microscopy revealed that a majority of the transfected Phoenix cells expressed EGFP. The transfection frequency using this method varied from $50 \%-80 \%$ as determined by flow cytometry (data not shown). For production of recombinant retrovirus, the cells were fed with fresh growth medium and placed at $32^{\circ} \mathrm{C}$ for $24 \mathrm{~h}$. The supernatants containing packaged recombinant viral RNA were collected, filtered and stored at $-80^{\circ} \mathrm{C}$.

\section{Titration of Recombinant Retrovirus}

The protocol of Miller et al. (17) was used to titer recombinant retroviruses. NIH-3T3 cells were plated at a concentration of $2 \times 10^{5}$ cells per well into 6well microplates $24 \mathrm{~h}$ before infection. PC- 3 cells were plated at $8 \times 10^{4}$ cells per well into 24-well microplates (Corning Costar). Viral dilutions were made from the supernatant of Phoenix cells producing recombinant retroviruses. Polybrene (hexadimethrine bromide; Sigma, St. Louis, MO, USA) was added (final concentration, $8 \mu \mathrm{g} / \mathrm{mL}$ ) to facilitate infection $(8,17)$. Cells and virus were incubated at $32^{\circ} \mathrm{C}$ for $24 \mathrm{~h}$. After $48 \mathrm{~h}$, EGFP-expressing cells were counted using the calibrated reticule in the eyepiece of the microscope. The total number of positive cells per well was estimated from counting green cells in ten distinct regions of the well. The viral titer was determined by multiplying the number of positive cells per well by the viral dilution. Since some cell division might have taken place between infection and counting, obvious doublets were counted as one infection event. Cells expressing $\beta$-galactosidase ( $\beta$-gal) were fixed, stained and counted $48 \mathrm{~h}$ after infection using the $\beta$-Gal Staining Kit (Invitrogen, San Diego, CA, USA). In the experiments described below, the multiplicity of infection (MOI) was determined by infection of NIH-3T3 cells.

\section{Analysis of EGFP Expression Using Flow Cytometry}

Flow cytometric analysis was carried out on a FACScan ${ }^{\mathrm{TM}}$ Flow Cytometer (Becton Dickinson Immunocytometry Systems, San Jose, CA, USA) using a 488-nm excitation source and a 530/30$\mathrm{nm}$ band-pass filter set. Six days after infection, the cells were trypsinized and resuspended at a concentration of $2-5 \times$ $10^{5}$ cells $/ \mathrm{mL}$. The florescence distribution was analyzed using Lysis II software (Becton Dickinson).

\section{Analysis of EGFP Expression Using Intracellular Fluorescence}

The intracellular expression of EGFP can be detected using a PerSeptive Biosystems' Cytofluor ${ }^{\circledR} 2350$ Fluorescence Plate Reader (PE Biosystems, Framingham, MA, USA). This instrument is equipped with $485 / 20$-nm excitation and 530/25-nm emission filters for detection of EGFP. Mock-infected cultures were used to determine the background fluorescence due to medium, cells and plastic. The background was also determined by reading the plates three days after infection when very low levels of EGFP are expressed. The maximum fluorescence is seen at six days post-infection. This signal is due primarily to EGFP expression, since the intrinsic fluorescence coming from the cells represents less than $10 \%$ of the total signal (data not shown).

\section{RESULTS}

\section{Titer of Recombinant Retroviruses}

In the EGFP expression plasmid, pNOLein, expression of the EGFP

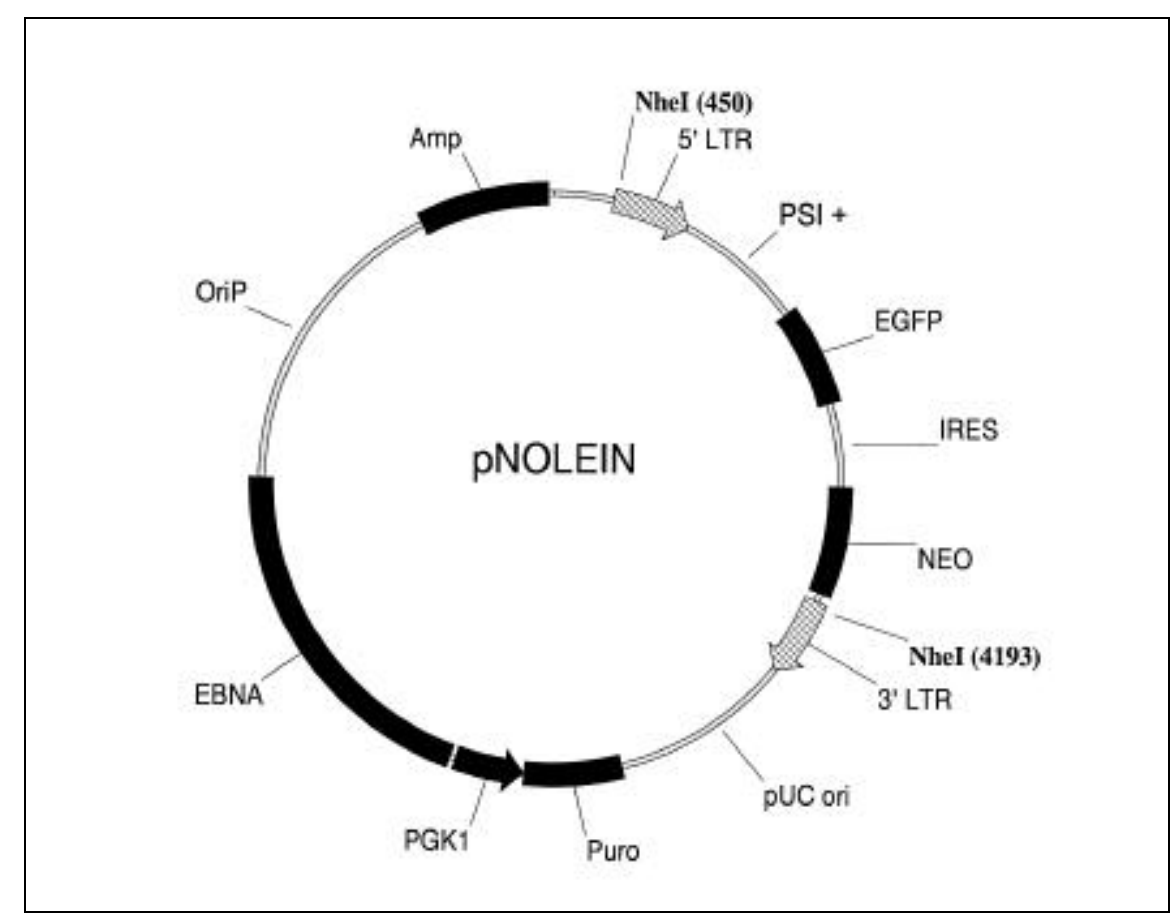

Figure 1. Schematic map of pNOLein. The 3.7-kb NheI fragment contains the coding regions for EGFP and $n e o$, downstream from the packaging site (PSI+). EGFP expression is driven by the 5' LTR promoter. The plasmid also contains the EBV OriP and nuclear antigen (EBNA). 
gene is driven by the $5^{\prime}$ long terminal repeat (LTR) promoter (Figure 1). The plasmid backbone from pLZRS$\operatorname{LacZ}(\mathrm{A})$ contains the EBV origin of replication (OriP) and the gene encoding EBNA1, both of which are required to maintain the plasmid episomally in the nucleus (12,20). Multiple plasmid copies generate high levels of genomic viral RNA for packaging $(8,12)$. Recombinant retrovirus was produced in Phoenix cells $(1,9,12,20)$.

The titers of pNOLein and pLZRSLacZ(A) were determined by infection of NIH-3T3 cells followed by directcounting positive cells using fluorescent or bright-field microscopy $(9,14$, 16). Table 1 gives the titer of the viral preparations, the method of analysis and the cell lines. The titer of the packaged pNOLein was similar to the titer of the packaged pLZRS-LacZ(A). Thus, the expression of EGFP following infection with the recombinant retrovirus was bright enough to allow quantitation by direct counting of infected cells. LacZ is often used as a marker for viral infection, but due to its large size, no other genes can be inserted into the viral genome (12). Since the EGFP protein comprises only 238 amino acid residues, there is ample space remaining in the recombinant viral genome to insert additional sequences $(2,9,21)$.

The titer of pNOLein was also determined directly in PC-3 cells using the fluorescent microscope. The fluorescent intensity of EGFP, by visual observation and quantitative flow cytometry (data not shown), was actually brighter in PC-3 cells than in NIH-3T3 cells. The titer of pNOLein on PC-3 cells $(7 \times$ $10^{5}$ i.p. $\left./ \mathrm{mL}\right)$ was very similar to the titer obtained on NIH-3T3 cells $(1.2 \times$ $10^{6}$ i.p./mL).

\section{Determination of Infection Frequencies in Target Cells}

Infection efficiencies of various target cell lines can be rapidly determined in a noninvasive manner by monitoring EGFP expression $(1-3,5,6,13,16,19)$. We assessed the infection frequency of pNOLein in PC-3 cells using fluorescent microscopy, analysis by a fluorescent microplate reader and flow cytometry. The inset of Figure 2 shows the
Table I. Titer of Recombinant Retrovirus Preparations

\begin{tabular}{|llcll|}
\hline $\begin{array}{l}\text { Plasmid Used for } \\
\text { Transfection }\end{array}$ & $\begin{array}{c}\text { Cell } \\
\text { Line }\end{array}$ & $\begin{array}{c}\text { Volume } \\
\text { Analyzed }\end{array}$ & Analysis Method & Titera \\
\hline $\begin{array}{l}\text { pNOLein } \\
\text { pLZRS-LacZ(A) }\end{array}$ & NIH-3T3 & $10 \mu \mathrm{L}$ & Fluorescent microscopy & $1.2 \times 10^{6}$ \\
pNOLein & PC-3 & $10 \mu \mathrm{L}$ & $\begin{array}{l}\text { X-gal staining } \\
\text { N-25 } \mu \mathrm{L}\end{array}$ & $\begin{array}{l}\text { Fluorescent microscopy } \\
\text { aTiter is given in infectious particles (determined by direct counting of cells ex- } \\
\text { pressing EGFP or } \beta \text {-gal) per mL. Duplicate points were averaged. }\end{array}$ \\
\hline
\end{tabular}

distribution of fluorescent cells determined by flow cytometry. The mean fluorescence of the EGFP-expressing cells was increased more than 100-fold compared to the uninfected PC-3 cells. The infection efficiency was calculated from the number of cells that shift to the region of positive fluorescence. Figure 2 (right axis) shows the infection rates determined by flow cytometry. An increase in the quantity of virus used for infection (MOI) led to an increase in infection efficiency. Since the EGFP signal in PC-3 cells was very strong, we also analyzed the PC-3-infected cells using a Cytofluor 2350 Fluorescent Plate Reader. The fluorescent units obtained from the microplate reader increased with increasing amounts of virus (Figure 2, left axis).

Both the flow cytometric analysis and the relative fluorescent units from the fluorescent plate reader show an increase in EGFP-expressing cells with increasing MOI. With flow cytometry, the infection efficiency increases up to an MOI of 2.5 when more than $26 \%$ of the PC-3 cells expressed EGFP. The data from the fluorescent plate reader show a similar increase in EGFP ex-

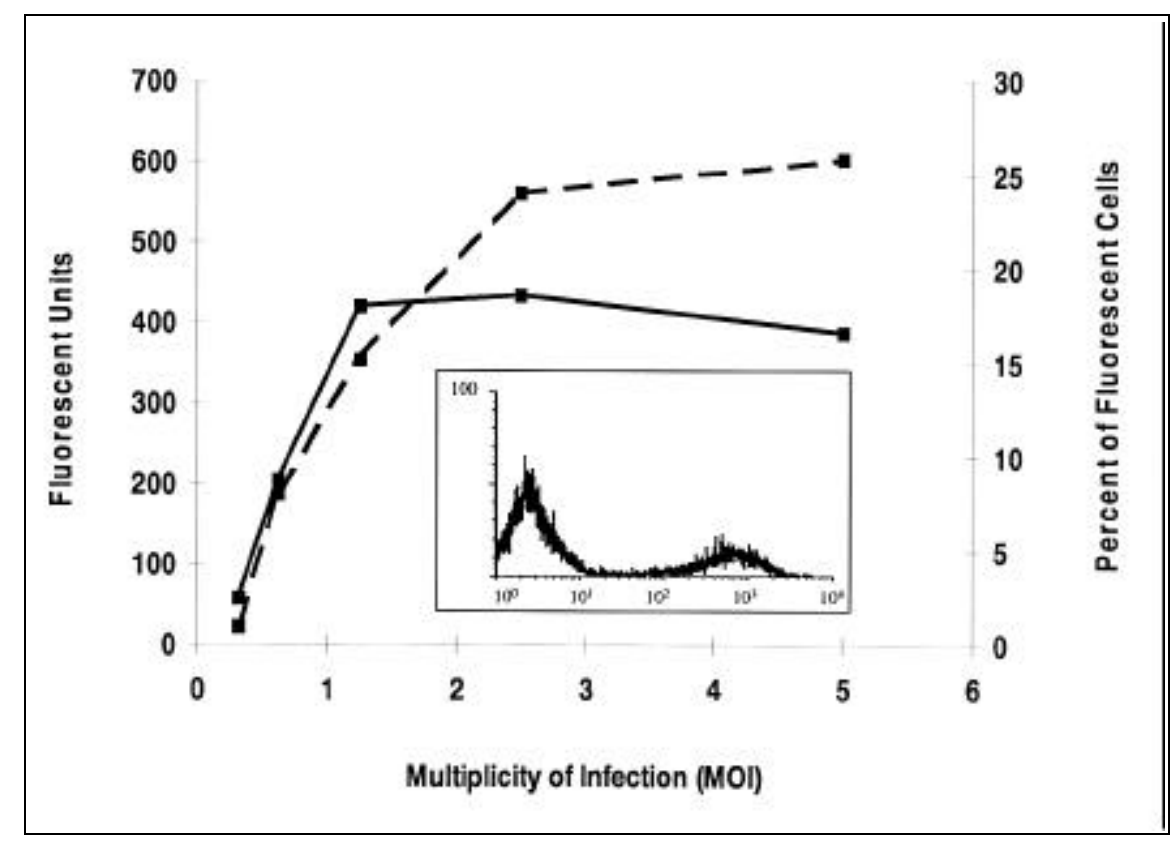

Figure 2. EGFP expression in infected cells. EGFP expression (solid line) in infected cultures was analyzed by flow cytometry and the Cytofluor 2350 Fluorescence Plate Reader. The inset represents the distribution of EGFP-expressing cells obtained by flow cytometric analysis of the culture infected with pNOLein at an MOI of 5. The Y-axis represents number of cells, while the $\mathrm{X}$-axis refers to relative fluorescent intensity. The percent of EGFP-expressing cells (dashed line) was calculated by dividing the number of EGFP-expressing cells measured by flow cytometry by the total number of cells counted. The cells were also analyzed for EGFP expression using the Cytofluor 2350 Fluorescent Plate Reader. The background value was obtained by measuring the fluorescent units in a well of mock-infected cells. This value (2122 fluorescent units) was subtracted from all of the data points. 
pression that plateaus at an MOI of 1.26. Thus, the increase in infection frequency determined by flow cytometry correlates well with an increase in EGFP expression measured by the fluorescent plate reader.

\section{Optimization of Infection Parameters}

In the experiment shown in Figure 2, the infection parameters for PC-3 cells were not optimized. Since the flow cytometric analysis and the data from the fluorescent plate reader showed good correlation, we used this later analytical technique to optimize conditions for viral infection. A matrix experiment was set up in 96-well plates in which the variables were cell density and MOI. PC-3 cells were plated at densities ranging from 1900-13800 cells per well and infected with increasing amounts of pNOLein virus up to an MOI of 7. The infected cultures were analyzed with the fluorescent plate reader on days 3, 6 and 8. Maximal expression of EGFP was seen on day 6 . Since cells were plated at multiple densities and received different virus treatments, the fluorescent units on day 3 were used as background values to sub- tract the fluorescence due to cells, medium and plastic. Figure 3 shows the increase in fluorescent units due to EGFP expression between days 3 and 6 following infection. The maximal level of EGFP expression was seen at the initial plating density of 6000 cells per well. The level of EGFP expression increased with increasing amounts of virus up to an MOI of 3. Using the optimized cell density and MOI, we were able to increase the infection frequency in PC-3 cells up to $70 \%$ (analysis by flow cytometry, data not shown).

\section{DISCUSSION}

Our results demonstrate the utility of using EGFP as a noninvasive marker to follow gene transfer after transfection and viral infection. EGFP-positive cells can be counted directly with a fluorescent microscope. Transfection efficiencies and viral titers can be obtained quickly, and cultures are not subjected to toxic agents. In the case of the pNOLein virus used in this study, there was very little difference in viral titer when measured on NIH-3T3 or PC-3 cells. Thus, viral infection can be evaluated directly in the target cell line.

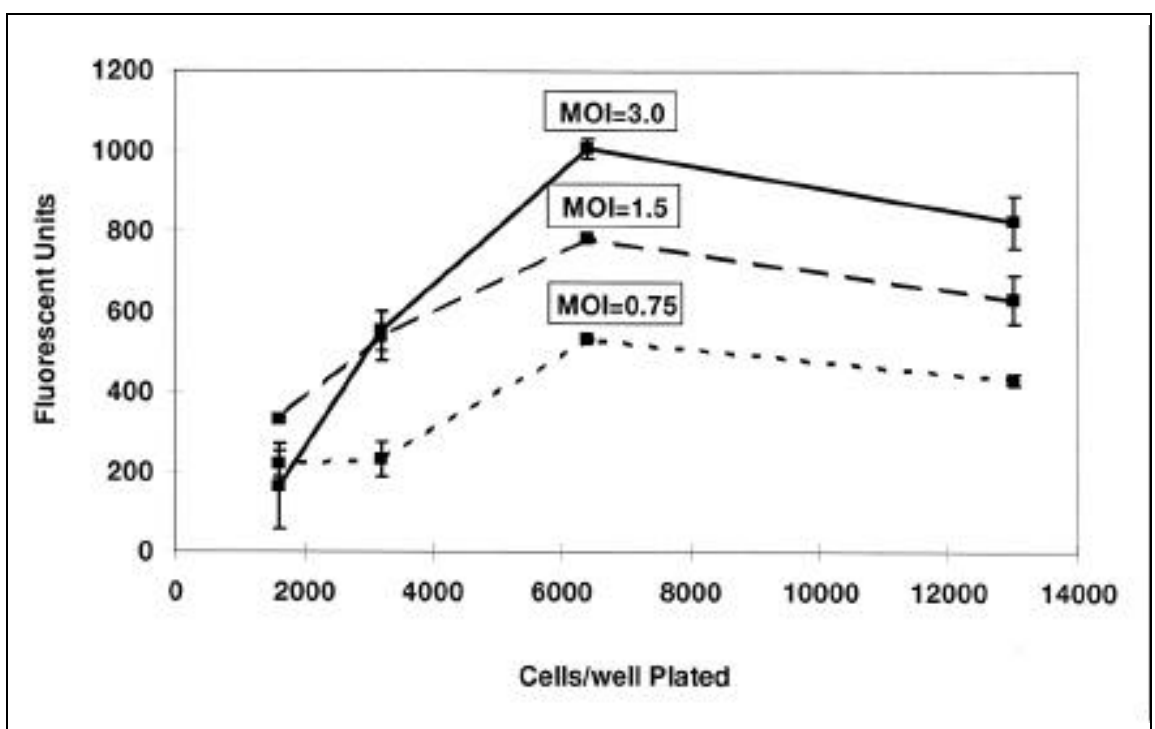

Figure 3. Optimization of infection parameters using EGFP expression. PC-3 cells were plated in 96-well plates at the densities indicated and infected with three different viral dilutions in duplicate wells. Infected cultures were analyzed for EGFP expression 3 and 6 days after infection using the Cytofluor 2350 Fluorescent Plate Reader. The values represent the increase in fluorescence between the two time points for each cell density and at each volume of virus. The volumes of virus added were 10 (solid line), 5 (dashed line) and $2.5 \mu \mathrm{L}$ (dotted line). The final MOI for 6000 cells per well is indicated in boxes above the data points. 
EGFP expression in infected cells can also be monitored in microplates with a fluorescent plate reader. The infection frequency determined by flow cytometric analysis correlated with EGFP expression quantified by the fluorescent plate reader. In contrast to flow cytometry, multiple determinations of EGFP expression can be made on different days in the same plate. Thus, the data from the plate reader can generate real-time data for determining growth parameters of infected or transfected cells. The strong fluorescent signal makes EGFP a useful marker for cell proliferation, allowing the growth of transfected and infected cells expressing EGFP to be monitored in a background of noninfected cells.

The ability to quantify infected cells is useful in heterologous cells infected with with recombinant retroviruses since infection efficiency can be less than $100 \%$ (13). However, in some cell lines, the signal from our retroviral vector was not strong enough to be detected over the intrinsic cell fluorescence. In those cell lines, we found that EGFP expression could be monitored following transfection with a multicopy EGFP expression plasmid, such as the ones used to produce viral RNA in the packaging cell line. In some cell lines, the over-expression of EGFP can be toxic (10). EGFP expression from retroviral vectors has not affected the cell viability or growth rates in any of the cell lines we have analyzed (data not shown). However, over-expression of EGFP from a multicopy plasmid was seen to be toxic in several cell lines (data not shown). The results presented here suggest that EGFP will be a very useful marker to characterize and specifically follow cells that have been altered by co-expression of an exogenous gene or target sequence.

\section{ACKNOWLEDGMENTS}

The authors would like to thank John McClary, Paul Romero and Aaron Lee for sequencing the plasmid. Ted Lau was instrumental in setting up the fluorescent microscope for use with virally infected cells. Paul Johnson and Rick Harkins provided helpful comments in the preparation of the manuscript.

\section{REFERENCES}

1.Anderson, M.T., I.M. Tjioe, M.C. Lorincz, D.R. Parks, L.A. Herzenberg, G.P. Nolan and L.A. Herzenber. 1996. Simultaneous fluorescence-activated cell sorter analysis of two distinct transcriptional elements within a single cell using engineered green fluorescent proteins. Proc. Natl. Acad. Sci. USA 93:85088511.

2.Aran, J.M., M.M. Gottesman and I. Pastan. 1998. Construction and characterization of bicistronic retroviral vectors encoding the multidrug transporter and $\beta$-galactosidase or green fluorescent protein. Cancer Gene Ther. 5:195206.

3.Bierhuizen, M.F.A., Y. Westerman, T.P. Visser, W. Dimjati, A.W. Wognum and F. Wagemaker. 1997. Enhanced green fluorescent protein as selectable marker of retroviral-mediated gene transfer in immature hematopoietic bone marrow cells. Blood 90:3304-3315.

4.Bierhuizen, M.F.A., Y. Westerman, T.P. Visser, A.W. Wognum and F. Wagemaker. 1997. Green fluorescent protein variants as markers of retroviral-mediated gene transfer in primary hematopoietic cells and cell lines. Biochem. Biophys. Res. Commun. 234:371-375.

5.Chalfie, M., Y. Tu, G. Euskirchen, W. Ward and D.C. Prasher. 1994. Green fluorescent protein as a marker for gene expression. Science 263:802-805.

6.Cheng, L., J. Fu, A. Tsukamoto and R.G. Hawley. 1996. Use of green fluorescent protein variants to monitor gene transfer and expression in mammalian cells. Nature Biotechnology 14:606-614.

7.Danos, O. and R.C. Mulligan. 1988. Safe and efficient generation of recombinant retroviruses with amphotropic and ecotropic host ranges. Proc. Natl. Acad. Sci. USA 85:6460-6464.

8.Finer, M.H., T.J. Dull, L. Qin, D. Farson and M.R. Roberts. 1994. kat: A high-efficiency retroviral transduction system for primary human T lymphocytes. Blood 83:43-50.

9.Grignani, F., T. Kinsella, A. Mencarelli, M. Valtieri, D. Riganelli, F. Grignani, L. Lanfrancone, C. Peschle, G.P. Nolan and R.G. Pelicci. 1998. High-efficiency gene transfer and selection of human hematopoietic progenitor cells with a hybrid ebv/retroviral vector expressing the green fluorescence protein. Cancer Res. 58:14-19.

10.Hanazono, Y., J.-M. Yu, C.E. Dunbar and R.V.B. Emmons. 1997. Green fluorescent protein retroviral vectors: low titer and high recombination frequency suggest a selective disadvantage. Hum. Gene Ther. 8:1313-1319.

11.Heim, R., A.B. Cubitt and R.Y. Tsien. 1995. Improved green fluorescence. Nature 373:663664.

12.Kinsella, T. and G.P. Nolan. 1996. Episomal vectors rapidly and stably produce high-titer recombinant retrovirus. Hum. Gene Ther. 7:1405-1413

13.Klein, D., S. Indraccolo, K. von Rombs, A. Amadori, B. Salmons and W.H. Gunzburg. 1997. Rapid identification of viable retrovirustransduced cells using the green fluorescent protein as a marker. Gene Ther. 4:1256-1260.

14.Levenson, V.V., E.D.E. Transue and I.B. Roninson. 1998. Internal ribosomal entry site- containing retroviral vectors with green fluorescent protein and drug resistance markers. Hum. Gene Ther. 9:1233-1236.

15.Li, X., N. Ngo, C. Hou, S. Cummingham, R.B. Zhang, Z. Li and C.-C. Huang. 1998. Screening for positive transfected clones with coexpressed green fluorescent protein. BioTechniques 24:52-55.

16.Limon, A., J. Brones, R. Puig, M. Carmona, O. Fornas, J.A. Cancelas, M. Nadal, J. Garcia, F. Rueda and J. Barquinero. 1997. Hightiter retroviral vectors containing the enhanced green fluorescent protein gene for efficient expression in hematopoietic cells. Blood 90:3316-3321.

17.Miller, A.D., D.G. Miller, J.V. Garcia and C.M. Lynch. 1993. Use of retroviral vectors for gene transfer and expression. Methods Enzymol. 218:581-599.

18.Mosser, D.D., A.W. Caron, L. Bourget, P. Jolicoeur and B. Massie. 1997. Use of a dicistronic expression cassette encoding the green fluorescent protein for the screening and selection of cells expressing inducible gene products. BioTechniques 22:150-161.

19.Muldoon, R.R., J.P. Levy, S.R. Kain, P.A. Kitts and C.J. Link, Jr. 1997. Tracking and quantification of retroviral-mediated transfer using a completely humanized, red-shifted green fluorescent protein gene. BioTechniques 22:162-167.

20.Pear, W.W., G.P. Nolan, M.L. Scott and E. Baltimore. 1993. Production of high-titer helper-free retroviruses by transient transfection. Proc. Natl. Acad. Sci. USA 90:83928396.

21.Persons, D.A., J.A. Allay, E.R. Allay, R.J. Smeyne, R.A. Ashmun, B.P. Sorrentino and A.W. Nienhuis. 1997. Retroviral-mediated transfer of the green fluorescent protein into murine hematopoietic cells facilitates scoring and selection of transduced progenitors in vitro and identification of genetically modified cells in vivo. Blood 90:1777-1786

22.Stauber, R.H., K. Horie, P. Carney, E.A. Hudson, N.I. Tarasova, G.A. Gaitanaris and G.N. Pavlakis. 1998. Development and applications of enhanced green fluorescent protein mutants. BioTechniques 24:462-471.

23.Yang, T.-T., L. Cheng and S.T. Kain. 1996. Optimized codon usage and chromophore mutations provide enhanced sensitivity with the green fluorescent protein. Nucleic Acid Res. 24:4592-4593.

24.Zhang, G., V. Gurtu and S.R. Kain. 1996. An enhanced green fluorescent protein allows sensitive detection of gene transfer in mammalian cells. Biochem. Biophys. Res. Commun. 227:707-711

Received 18 June 1998; accepted 16 February 1999.

\author{
Address correspondence to: \\ Dr. Linda Cashion \\ Department of Biological Research \\ Berlex Biosciences \\ 16049 San Pablo Avenue \\ P.O. Box 4099 \\ Richmond, CA 94804-0099, USA \\ Internet:linda_cashion@berlex.com
}

